Research Article

\title{
Whole-genome duplication and hemoglobin differentiation traits between allopatric populations of Brazilian Odontophrynus americanus species complex (Amphibia, Anura)*
}

\author{
Aurora M. Cianciarullo ${ }^{1}$ (iD. Claudia R. Bonini-Domingos ${ }^{2}$, Luiz D. Vizotto ${ }^{3}$, Leonardo S. Kobashi ${ }^{4,5}$, \\ Maria-Luiza Beçak ${ }^{1}$ and Willy Beçak ${ }^{1}$ \\ ${ }^{1}$ Laboratory of Genetics, Instituto Butantan, São Paulo, SP, Brazil. \\ ${ }^{2}$ Department of Biology, Laboratory of Hemoglobins and Genetics of the Hematological Diseases, \\ Universidade Estadual Paulista "Julio de Mesquita Filho (UNESP), São José do Rio Preto, SP, Brazil. \\ ${ }^{3}$ Department of Zoology, Universidade Estadual Paulista "Julio de Mesquita Filho (UNESP), São José do \\ Rio Preto, SP, Brazil. \\ ${ }^{4}$ Laboratory of Ecology and Evolution, Instituto Butantan, São Paulo, SP, Brazil. \\ ${ }^{5}$ Universidade Paulista (UNIP) São Paulo, SP, Brazil.
}

\begin{abstract}
Two allopatric populations of Brazilian diploid and tetraploid Odontophrynus americanus species complex, both from São Paulo state, had their blood hemoglobin biochemically analyzed. In addition, these specimens were cytogenetically characterized. Biochemical characterization of hemoglobin expression showed a distinct banding pattern between the allopatric specimens. Besides this, two distinct phenotypes, not linked to ploidy, sex, or age, were observed in adult animals of both populations. Phenotype A exhibits dark-colored body with small papillae, ogivalshaped jaw with reduced interpupillary distance and shorter hind limbs. Phenotype B shows yellowish-colored body with larger papillae, arch-shaped jaw with broader interpupillary distance and longer hind limbs. Intermediate phenotypes were also found. Considering the geographical isolation of both populations, differences in chromosomal secondary constrictions and distinct hemoglobins banding patterns, these data indicate that $2 n$ and $4 n$ populations represent cryptic species in the $O$. americanus species complex. The observed phenotypic diversity can be interpreted as population genetic variability. Eventually future data may indicate a probable beginning of speciation in these Brazilian frogs. Such inter- and intrapopulational differentiation/speciation process indicates that $O$. americanus species complex taxonomy deserves further evaluation by genomics and metabarcoding communities, also considering the pattern of hemoglobin expression, in South American frogs.
\end{abstract}

Keywords: Anura, cryptic species, hemoglobin differentiation, polyploidy, whole-genome duplication.

Received: September 19, 2017; Accepted: July 25, 2018

\section{Introduction}

After Susumu Ohno's proposal of evolution by whole-genome duplication (WGD) as a primordial pathway for evolutionary innovations (Ohno, 1970), the speciation process has drawn close attention from evolutionary biologists (Huminiecki and Conant, 2012; Ezaz and Deakin, 2014). The use of Mathematical Physics concepts to predict the development of species allowed for computer simulation, indicating that species differentiation may arise without geographical isolation, in line with the Neutral

Send correspondence to Aurora M. Cianciarullo. Laboratory of Genetics, Butantan Institute, Av. Dr. Vital Brasil 1500, 05503-900 São Paulo, SP, Brazil. E-mail: aurora.cianciarullo@ butantan.gov.br *This work celebrates the first description of polyploidy in vertebrates, 50 years ago.
Theory, which states that species diversity results from random processes acting on similar populations. This method simulates hypothetical evolution process of a virtual population over hundreds of generations (de Aguiar et al., 2009). It is now common sense that genetic differences do not accumulate only when a population is forced into geographical isolation: the emergence of new species can occur over partial insulation only, or even independently of any geographical barriers (Martins et al., 2013). Thus, some traditional organizational principles no longer provide a satisfactory framework, such as the classification of speciation mechanisms by geographical context in allopatric, parapatric and sympatric categories. There is a great debate to promote changes in the classical methodologies about speciation settings and biodiversity (Marie Curie 
SPECIATION Network et al., 2012; Lemos-Costa et al., 2017).

The fossorial South American frogs of the genus Odontophrynus form a distinctive and phylogenetically compact group of warty toad-like burrowers, readily distinguished from other members of the same former Leptodactylidae family (Savage and Cei, 1965), which have been recently submitted to phylogenetic analyses that led to a taxonomic revision and consequent reclassification of the genus Odontoprhynus as part of the Odontophrynidae family (Anura: Neobatrachia) (Pyron and Wiens, 2011). In this genus, only one species - Odontophrynus americanus presents the phenomenon of polyploidy, the first reported occurrence in bisexual natural vertebrate species (Beçak et al., 1966).

At the same year, Sáez and Brum-Zorilla (1966) found chromosome variation in Odontophrynus americanus (Amphibia-Anura), which they described as multiple translocations.

Presently, many other distinct bisexual polyploid lineages of amphibians are known, such as the tetraploid, hexaploid, and octaploid frogs, which exist as normally reproducing bisexual population or species (Beçak et al., 1967a, b; Bogart, 1980; Kobel and Pasquier, 1986; Tymowska, 1991). Triploid hybrid specimens $(3 n=33)$ were obtained artificially at first by crossing a male $O$. cultripes $(2 \mathrm{n}=22)$ with a female $O$. americanus $(4 \mathrm{n}=44)$ (Beçak et al., 1970). The gametes of these $3 n$ (bred for five years in the laboratory) were analyzed. These specimens formed abnormal aneuploid and normal euploid gametes. So although some cells had irregular numbers of chromosomes, others had complete numbers like $n, 2 n$ and $3 n$ (Beçak and Beçak, 1970). These gametes could lead to the emergence of higher levels of ploidy, such as hexaploidy (Beçak and Beçak, 1970). Natural triploids and hexaploids were actually discussed in the literature (Batistic et al., 1973; Ruiz et al., 1980, 1981). Gradually, cryptic species or morphologically similar diploid species are being set apart from those they are thought to have evolved from (Beçak et al., 1970; Bogart and Wasserman, 1972; Batistic et al., 1975; Bogart and Tandy, 1976; Mahoney and Robinson, 1980; Tymowska and Fischberg, 1980). More recently, a natural interspecific hybrid between Odontophrynus cordobae and O. occidentalis specimen belonging to the Odontophrynus species complex was documented (Pereyra et al., 2009), sharing exosomatic and chromosomal characteristics of both species. Thus, polyploidy seems to be of considerable evolutionary importance in some vertebrate groups. It is possible that polyploidization occurred frequently during the evolution of higher organisms, with ulterior evolution into a diploid state by chromosomal rearrangement and subsequent diversification of species (Ohno, 1970; Beçak and Beçak, 1974a, 1998; Sparrow and Nauman, 1976; Leipoldt and Schmidtke, 1982; Mable and Bogart, 1995;
Beçak and Kobashi, 2004; Huminiecki and Conant, 2012; Beçak, 2014).

Speciation seems to be occurring in our experimental model of the diploid and tetraploid O. americanus species complex, not only at the geographical isolation level. Despite their reproductive isolation, diploid and tetraploid specimens collected in the state of São Paulo, Brazil, are morphologically indistinguishable from each other, and also from the holotype deposited at the Museum of Natural History in Paris, which was collected in Buenos Aires, Argentina (Miranda-Ribeiro, 1920). The same is true for the Argentine- Uruguayan populations (Barrio and Pistol de Rubel, 1972). Odontophrynus lavillai (Cei, 1985) encompasses diploid populations from Santiago del Estero that were analyzed formerly by Barrio and Pistol de Rubel (1972), with the denomination O. americanus referring exclusively to tetraploid specimens (Cei, 1985, corroborated by Rosset et al., 2006, and followed by several authors, as Rocha et al., 2017). Also, O. cordobae was described as diploid population (Martino and Sinsch, 2002), followed by $O$. maisuma (Rosset, 2008), and more recently, $O$. juquinha (Rocha et al., 2017).

In the present study we performed a biochemical analysis of the expressed hemoglobins from Brazilian populations of diploid and tetraploid $O$. americanus species complex specimens and we compared them with data found in the literature.

\section{Materials and Methods}

\section{Specimens}

Eight living adult diploid Odontophrynus americanus species complex from Botucatu and eight living adult tetraploid O. americanus species complex from São Roque both inner cities of the state of São Paulo, Brazil - weighting 6-18 g, were used.

All guidelines set by the Biodiversity Information and Licensing System / Chico Mendes Institute for Biodiversity Conservation (SISBIO/ICMBio) were complied with. The Biodiversity Committee of the Butantan Institute and the Ministry of Environmental Affairs, through the Brazilian Institute of Environment and Renewable Natural Resources (IBAMA - Process: 02001.005160/2008) have endorsed the present study. Sub-samples used in this study were deposited at the Alphonse Richard Hoge Herpetological Collection - Butantan Institute, in conformity with resolutions of its Genetic Heritage Management Board (CGEN No.147, June 29, 2006. Odontophrynus americanus - Registry Number: IBSPCR 0677-0618).

\section{Karyotyping}

Mitotic chromosomes in metaphase were obtained from two animals randomly chosen from the two populations. They were injected subcutaneously with a single dose of $200 \mu \mathrm{L} / 10 \mathrm{~g}$ body weight of $1 \%$ colchicine in saline solu- 
tion. After 2 hours, fragments of intestine of about $1 \mathrm{~mm}$ were collected, placed in cold distilled water for $15 \mathrm{~min}$, and fixed for $20 \mathrm{~min}$ in a $50 \%$ acetic acid solution, before squashing between slide and coverslip. Coverslips were removed in dry ice; the preparations were hydrolyzed for 10 min at $60{ }^{\circ} \mathrm{C}$ with $\mathrm{HCl} 1 \mathrm{~N}$, and then stained for 15 min with $2 \%$ Giemsa in distilled water, at room temperature (Beçak et al., 1966).

\section{Cellulose acetate electrophoresis of hemoglobins} $(\mathrm{Hb})$

Ten blood samples of $5 \mu \mathrm{L}$ were collected from each animal group in 10\% EDTA (4:1), hemolyzed in 1\% saponin (1:1), homogenized and submitted to cellulose acetate electrophoresis, performed using Tris-EDTA-Borate Buffer (TEB) $\mathrm{pH} 8.6$ at $300 \mathrm{~V}$ for $40 \mathrm{~min}$. The bands were stained with $0.5 \%$ Ponceau (Naoum, 1990). A $5 \mu \mathrm{L}$ sample of human blood was collected from a healthy volunteer donor and used as control. Carbonic anhydrase was used as a loading control.

\section{Isoelectric focusing of $\mathrm{Hb}$}

A $0.2 \%$ agarose gel was prepared in bi-distilled water,

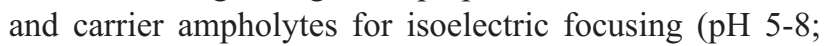
6.5-9 and 3-10) were immediately added. Three fresh $5 \mu \mathrm{L}$ blood samples from each animal group were hemolyzed by osmotic lysis: cells were rinsed 3 times in $0.8 \% \mathrm{NaCl}$, and 3 to 5 volumes of distilled water per volume of rinsed erythrocytes were added. Samples were applied and electrophoresis was performed at $5 \mathrm{~mA}$ until samples were transferred to the gel and migration began. The current was then increased to $8 \mathrm{~mA}$ for $40 \mathrm{~min}$ at $4{ }^{\circ} \mathrm{C}$. After running the gel was fixed for $3 \mathrm{~min}$ with $10 \mathrm{~mL}$ of $20 \%$ Tri-chloride-acetic acid (TCA), and rinsed in distilled water for $2 \mathrm{~min}$. Gels were dehydrated for 12 to $15 \mathrm{~h}$ at room temperature, and then stained for 10 to 15 min with $5.5 \%$ Ponceau or $0.6 \%$ Starch Black (Naoum, 1990).

\section{Globin chains electrophoresis}

Tris-EDTA-borate (TEB)-urea buffer $\mathrm{pH} 8.6$ was prepared and maintained by agitation until use at room temperature. Three samples of $5 \mu \mathrm{L}$ from each animal group were prepared by addition of $50 \mu \mathrm{L}$ TEB-urea and $50 \mu \mathrm{L}$ $\beta$-mercaptoethanol to $50 \mu \mathrm{L}$ hemolyzed blood cells, following incubation for $30 \mathrm{~min}$ at room temperature. Then, $6.4 \mathrm{~mL}$ of $\beta$-mercaptoethanol were added to the TEB-urea running buffer, and the samples were applied exactly at the center of a cellulose acetate sheet. Electrophoresis was performed at $150 \mathrm{~V}$ for $80 \mathrm{~min}$. The resulting bands were stained with $0.5 \%$ Ponceau or $0.6 \%$ Starch Black (Naoum, 1990).

\section{Agar gel electrophoresis of $\mathrm{Hb}$ at acid $\mathrm{pH}$}

Agar gels were prepared by adding $200 \mathrm{mg}$ of Bactoagar (Difco Lab) to $20 \mathrm{~mL}$ of phosphate buffer $\mathrm{pH} 6.2$, and phosphate buffer $\mathrm{pH} 6.2$ was used in both electrolytic compartments. Three blood samples of $5 \mu \mathrm{L}$ from each animal group were applied exactly at the center of the agar gel. Electrophoresis was performed at $100 \mathrm{~V}$ for $20 \mathrm{~min}$. The resulting bands were stained with $0.5 \%$ Ponceau (Naoum, 1990).

\section{Results}

\section{Biological characterization}

Eight diploid and eight tetraploid $O$. americanus species complex were collected respectively in the surroundings of Botucatu and São Roque cities, state of São Paulo, Brazil. The cities are $154 \mathrm{~km}$ apart and there was no overlapping in populations of $2 \mathrm{n}$ and $4 \mathrm{n}$ animals in both collecting areas. The animals remained burrowed beneath the ground during the day and came to surface at night, to look for food or to mate. Most frogs were captured during the breeding season, which occurs in rainy days of JanuaryMarch, or sporadically in July-August. Differences in the sound spectrum of mating calls were observed between diploid and tetraploid animals during this period, as previously noted in Argentinian populations (Bogart and Wasserman, 1972; Martino and Sinsch, 2002).

Two distinct phenotypes were observed in the adult animals of both populations, whose characteristics were not linked to ploidy, sex or age (Figure 1). Individuals with intermediate phenotypes, but with characteristics of both phenotypes could also be observed. Phenotype A displayed head length almost as large as head width, increased interpupillary distance, light yellowish color and larger papillae on the dorsal skin, intense yellowish colors and lines at the mouth skin around the superior jaw, and longer hind limbs (Figure 1, left side). Phenotype B displayed ogival head, dark color, smaller dorsal skin papillae and shorter hind limbs. Patterns and colors on the mouth skin were usually almost imperceptible (Figure 1, right side).

\section{Cytogenetic characterization}

Karyotypes from two living and recently captured animals were performed, confirming the degree of ploidy according to the locality where the frogs were collected. Diploids $O$. americanus $(2 \mathrm{n})$ species complex presented 22 chromosomes, with satellites on pairs 4 and 11 . Tetraploids O. americanus (4n) species complex presented 44 chromosomes, with satellites on both pairs 11 (Figure 2).

\section{Biochemical characterization}

Blood of living $O$. americanus species complex specimens collected in Botucatu (2n) and São Roque (4n) was used for biochemical assays. Electrophoretic fractionation of $\mathrm{Hb}$, performed in cellulose acetate, revealed four distinct 

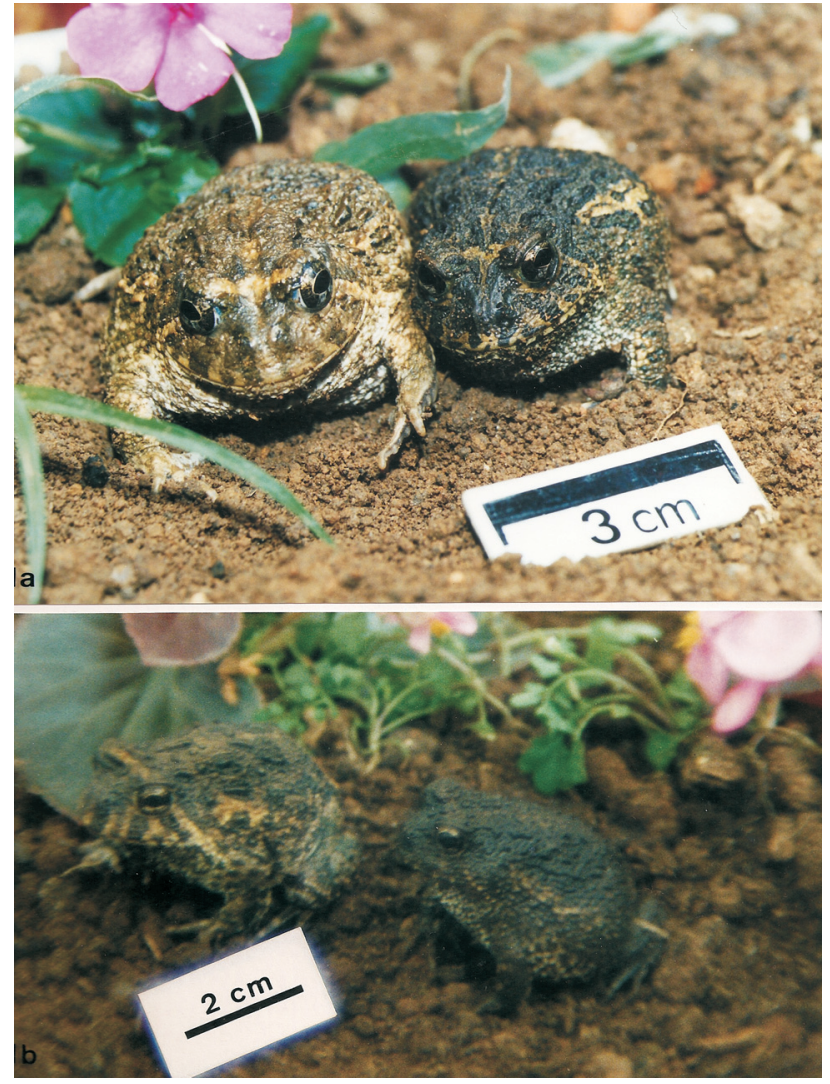

Figure 1 - Odontophrynus americanus species complex phenotypes. (a) O. americanus species complex $4 \mathrm{n}$ (left) and $2 \mathrm{n}$ (right). Phenotype A is expressed by the tetraploid and phenotype $\mathrm{B}$ is expressed by the diploid. (b) O. americanus species complex $2 \mathrm{n}$ (left) and $4 \mathrm{n}$ (right). Phenotype $\mathrm{A}$ is expressed by the diploid and phenotype $\mathrm{B}$ is expressed by the tetraploid.

fraction bands in diploid individuals and three bands in tetraploid ones, where the first band apparently consists of two merged fractions (Figure 3).

In both diploids and tetraploids, two distinct globin types ( $\alpha$-like and $\beta 2$-like) were detected through globin chain electrophoresis, whose mobility pattern was substantially different from the current in human globin chains (Figure 4). Furthermore, a $\beta 1$-like chain was present only in diploids, while a $\gamma$-like chain was present only in tetraploids. These globins also presented a banding pattern which was different from those found in human globin chains.

The electrophoretic pattern of $\mathrm{Hb}$ detected by isoelectric focusing showed four distinct fractions or bands in both animals. While electrophoretic mobility was similar between the first and the fourth fractions or bands, it was distinct between the second and third ones (Figure 5).

Acid $\mathrm{pH}$ electrophoresis of hemoglobin from both animals showed no differences in the mobility pattern, with absence of polarity in $\mathrm{Hb}$ molecules at these experimental conditions. Both samples remained around the application point, indicating absence of variant or mutant hemoglobin besides the main $\mathrm{Hb}$ (Figure 6).
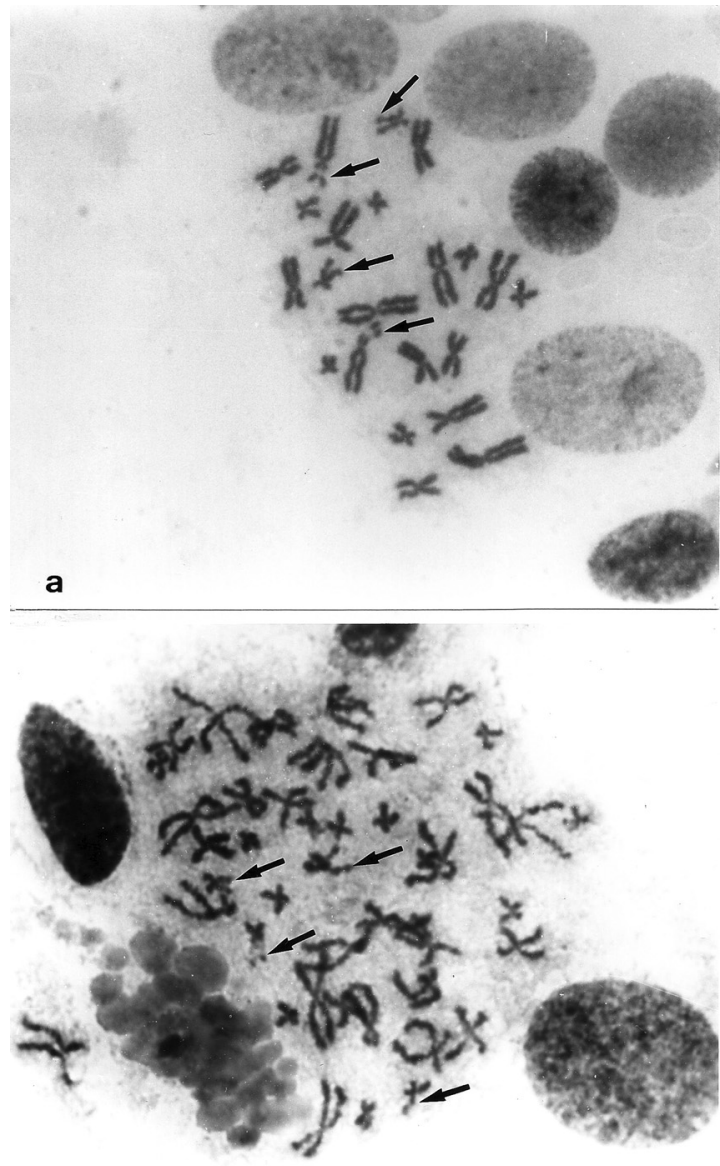

b

Figure 2 - Karyotypes confirming the degree of polyploidy. (a) $O$. americanus species complex $2 \mathrm{n}=22$ chromosomes, with satellites on pairs 4 and 11 (arrows); (b) O. americanus species complex $4 \mathrm{n}=44$ chromosomes, with satellites on both pairs 11 (arrows).

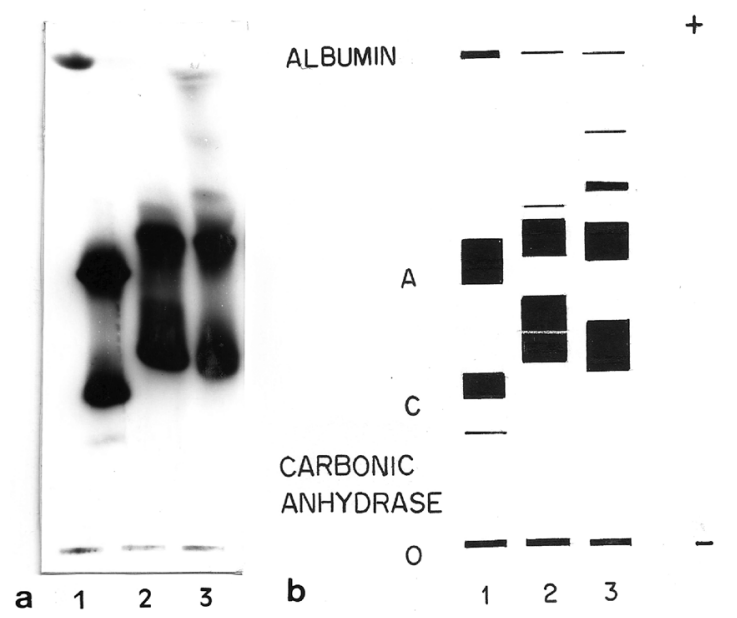

Figure 3 - Hemoglobin fractions. (a) Electrophoretic migration pattern of hemoglobin fractions in cellulose acetate. Lane 1: Human hemoglobin $\mathrm{AC}$; lane 2: O. americanus species complex 2n; lane 3: O. americanus species complex 4n. (b) Schematic representation of the electrophoretic migration pattern. 


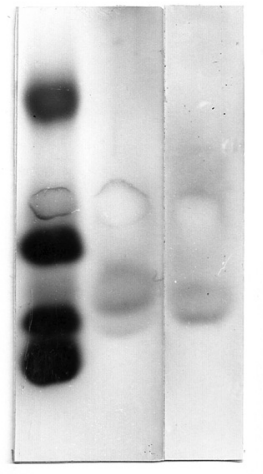

$\begin{array}{llll}\text { a } & 1 & 2 & 3\end{array}$ $\gamma$

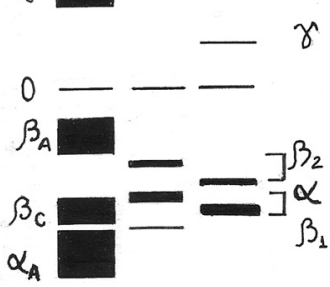

b

$\gamma$
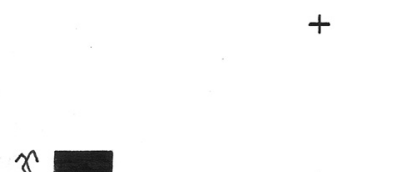

Figure 4 - Globin chains. (a) Globin chains electrophoresis performed in cellulose acetate. Lane 1: human hemoglobin AC; lane 2: diploid $O$. americanus species complex; lane 3: tetraploid $O$. americanus species complex. Three chains are present in all samples. Human chains correspond to globin $\alpha \mathrm{A}, \beta \mathrm{C}$ and $\beta \mathrm{A}$ and $\gamma$ from the negative pole, respectively. The two main globin chains of the diploid ( $\alpha$-like and $\beta 2$-like) present a migration pattern that is different from the corresponding main globin chains of the tetraploid. (b) Schematic representation of globin electrophoresis.
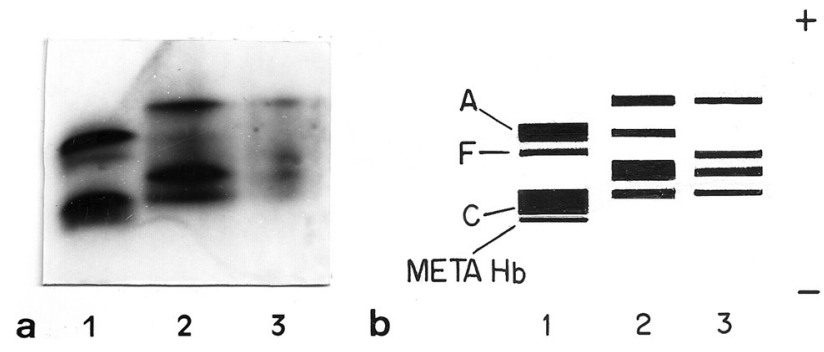

Figure 5 - Isoelectric focusing. (a) Migration pattern of hemoglobin fraction in agarose gel. Lane 1: human A, F (fetal), C and Meta Hb; lane 2: diploid $O$. americanus species complex; lane 3: tetraploid $O$. americanus species complex. Both amphibians presented four distinct bands. (b) Schematic representation of isoelectric focusing migration patterns.
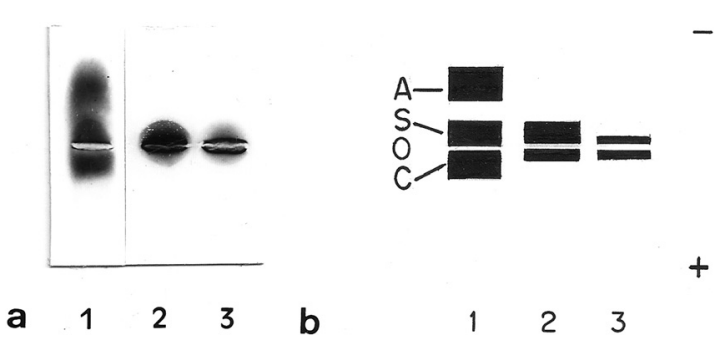

Figure 6 - Agar gel electrophoresis (a) Agar gel separation at acid pH electrophoresis did not allow differentiation of hemoglobin types between diploid and tetraploid $O$. americanus species complex. Lane 1: human A, S, and $\mathrm{C}$ hemoglobin; lane 2: diploid $O$. americanus species complex. (b) Schematic representation of acid $\mathrm{pH}$ electrophoretic migration patterns.

\section{Discussion}

The first discovery of animal polyploidy in natural bisexual species of vertebrates was made fifty years ago in the South American frog Odontophrynus americanus by Beçak and collaborators (Beçak et al., 1966). Since then, several studies were carried out with polyploid populations of $O$. americanus frogs, but much remains to be done, especially after the advent of new concepts and technologies in molecular biology, which encourages revisiting the past and reorganize the present, preparing for further investigations.

The mapping of the geographical distribution of diploid and tetraploid O. americanus in South America showed that diploids tend to live in lower-temperature, above-sea-level regions, from São Paulo to Rio Grande do Sul (Brazil) and in Córdoba (Argentina), whilst tetraploids live in warmer regions of Brazil, ranging from Minas Gerais, São Paulo, and Paraná to Rio Grande do Sul, as well as in Paraguay, Uruguay and Argentina (Beçak and Beçak, 1974b). Tetraploids are thus distributed in a wider area and in several ecological niches when compared to the diploids. Our results showed that diploid and tetraploid populations of the O. americanus species complex from the state of São Paulo [Botucatu ( $804 \mathrm{~m}$ above sea level) and São Roque (771 $\mathrm{m}$ above sea level) respectively] are allopatric, since both cities are $154 \mathrm{~km}$ distant from one another. Karyotypes of recently captured specimens confirmed the diploid and tetraploid conditions, with 22 and 44 chromosomes, respectively. However, sympatry of both diploid and tetraploid specimens of the O. americanus species complex had been found in the same pond at different seasons in Pirajuí and Guapiara, both in São Paulo state, Brazil (Ruiz et al., 1981) and at Santa Bárbara do Sul, in Rio Grande do Sul, southern Brazil (Ruiz et al., 1984) and these findings were recently reviewed (Beçak, 2014).

An extensive review about the geographic distribution of diploid and tetraploid populations of the $O$. americanus species complex was done by Rosset et al. (2006). The authors found a complex geographic pattern of populations with different ploidy, including areas of syntopy and sympatry, and they also report the occurrence of a naturally triploid specimen and the first record of B-chromosomes in the genus.

Differences in the sound spectrum of the mating calls were observed between the Brazilian diploid and the tetraploid frogs. These differences were recorded in Argentinian frogs (Bogart and Wasserman, 1972; Martino and Sinsch, 2002) and they evince the existence of a prenuptial isolation mechanism that, coupled with genetic incompatibility, are factors that contribute in maintaining both groups apart. Together with other sources of biochemical and genetic evidence it has been proposed that the Argentinian diploid $O$. americanus is a new cryptic species, named $O$. cordobae (Martino and Sinsch, 2002), O. lavillai (Cei, 1985), O maisuma (Rosset 2008), and O. juquinha (Rocha et al., 2017).

Our data demonstrate the occurrence of two phenotypes in both diploid and tetraploid Brazilian frog populations belonging to the Odontophrynus species complex, characterizing an intrapopulational polymorphism, which 
is maintained in sympatry if each population (diploids and tetraploids) is singularly considered, whereas it is in allopatry with regard to each other. An interpopulational difference was also observed in Argentina, in geographically isolated populations of diploid and tetraploid $O$. americanus, although intrapopulational polymorphism has not been detected (Barrio and Pistol de Rubel, 1972). Interpopulational differences were also reported between diploid and tetraploid O. americanus from Brazil and Argentina, attributed to the great distance that separates them (Barrio and Pistol de Rubel, 1972). Intra- and inter-specific morphometric variation was found between Odontophrynus populations of central Argentina (Grenat et al., 2012). Intrapopulational differences were also found in a tetraploid $O$. americanus population from Rio Cuarto (Córdoba, Argentina) (Barale et al., 1981), with three distinct phenotypes related to dorsal color and skin patterns. Based only on morphological parameters, their three detected phenotypes can be fitted to our phenotypes A and B. A described diploid species from Argentina has been designated as O. lavillai (Cei, 1985). Examination of photographic registry suggests that this species corresponds to the diploid and tetraploid $O$. americanus phenotype $\mathrm{B}$ described herein, as well as to a distinct diploid $O$. americanus previously described (Barrio and Pistol de Rubel, 1972). The observed phenotypic diversity found in phenotypes A and B can be interpreted as population genetic variability. Maybe in the future these data will be evaluated as indicative of the beginning of speciation in these Brazilian frogs. Therefore, it is clear that further studies with improved molecular biology tools are needed to clarify the correct taxonomic status of the Odontophrynus species complex.

The electrophoretic patterns of 6PGD and G6PD enzymes (Schwantes et al., 1969, 1977) revealed identical banding patterns in both $2 \mathrm{n}$ and $4 \mathrm{n} O$. americanus specimens, which could argue in favor of the hypothesis that the tetraploid $O$. americanus arose by autopolyploidy from the diploid $O$. americanus. On the other hand, there is also the possibility that allopolyploidy has occurred by mating between $O$. americanus $2 \mathrm{n}$ and $O$. occidentalis $2 \mathrm{n}$, or their ancestor, which would agree with the electrophoretic patterns of 6PGD and G6PD and with the finding that these two species are sympatric in Oriental Argentina (Barrio, 1964). A third possibility is that other species, now extinct, could have contributed to tetraploidy, since the Odontophrynidae family seems to have undergone extensive radiation throughout South America during the Eocene (Pyron and Wiens, 2011), and several geological events such as glaciation, aridness, or others occurred during and after this period, leading to speciation and a great diversity of groups (Savage, 1973).

The biochemical characterization of $\mathrm{Hb}$ resulted in distinct banding patterns between both diploid and tetraploid specimens. Variant or mutant Hbs were not detected. Phylogenetic reconstructions should be performed to assess the relative contributions of whole-genome duplication. The information obtained so far in relation to the in vivo erythropoiesis in these cryptic Brazilian O. americanus populations demonstrates differences at the physiological and molecular levels (Cianciarullo et al., 2000a,b), indicating that a speciation process is occurring and that the cladogenesis should be revised, independently of the morphological variations. New molecular methodologies as combined mitochondrial DNA, nuclear DNA, as well as morphological, genetic, and bioacoustics data should be useful to further characterize these cryptic species.

The most common classification of speciation modes begins with the spatial context in which divergence occurs: sympatric, parapatric, or allopatric. This classification is unsatisfactory because it divides a continuum into discrete categories, concentrating attention on the extremes. It also ignores the fact that speciation is a prolonged process that commonly has phases in different spatial contexts. It has been suggested that it is more productive to study the current balance between local adaptation and gene flow, the interaction between components of reproductive isolation and the genetic basis of differentiation (Butlin et al., 2008).

Regarding the O. americanus species complex, some specimens have received local taxonomic status and new nomenclatures over the years, sometimes without a broad community study that encompasses the four South American countries in which their natural habitat is located: Argentina, Brazil, Paraguay and Uruguay (Barrio, 1964; Barrio and Pistol de Rubel, 1972; Barale et al., 1981; Cei, 1985; Martino and Sinsch, 2002; Rosset et al., 2006, 2009; Rocha et al., 2017). A review of the geographic distribution of diploid and tetraploid populations of the Odontophrynus americanus species complex indicates an intricate geographic pattern of populations with different ploidy, including areas of syntopy and sympatry (Rosset et al., 2006). The tetraploid $O$. americanus presents three disconnected population groups, which are isolated from one another by diploid populations. One of these tetraploid groups is distributed along central and eastern Argentina, southern Brazil, southern Paraguay, and Uruguay, with the other two population groups inhabiting southeastern Brazil, and northwestern Argentina, respectively. Yet, Rosset et al. (2006) included the distribution of both diploid $O$. lavillai and $O$. cordobae, and presented new records of three more allopatric diploid population groups, referred to as Odontophrynus sp. Some of these population groups are associated with biogeographic regions. This review indicates that there is a complex distribution pattern of populations of different ploidy, including areas of syntopy and sympatry, and cytogenetic variability. This could indicate the presence of more species, the occurrence of auto- and allopolyploidy, and multiple origins of tetraploidy. Therefore, taxonomic work at the proteomics and genomics levels is needed to resolve this species complex, native from Argentina, Brazil, 
Paraguay, and Uruguay, and also found in several protected areas (Aquino et al., 2010).

Based on our findings we agree with the proposition made by Rosset et al. (2006) and Aquino et al. (2010) about the need of a more comprehensive study, which at our point of view ought to be carried out by an international consortium, with the active participation of representative researchers from South American countries, in order to assess the territory inhabited by the herpetofauna of the Odontophrynidae family in its maximum extension. Perhaps we shall be surprised by new records and even new species of the genus Odontophrynus in areas not previously surveyed, due to their irradiation in search for new habitats.

Barcoding is a DNA-based species identification, which is transforming the traditional approach to the study of biodiversity (Cristescu, 2014). A DNA barcode-based evaluation of the complex genus Odontophrynus could greatly contribute for a more precise taxonomic classification. This will be a challenge and incentive to the new generation of biologists, with the perspective on the Earth BioGenome Project (EBP) to sequence, catalog, and characterize the genomes of all of Earth's eukaryotic biodiversity (Lewin et al., 2018).

Assistance from the International Consortium for Zoomorphology Standards (Vogt et al., 2013; Deans et al., 2015) would be of great importance for the reorganization of the South American Odontophrynidae family, mainly considering the recent advancements in the computational analysis of phenotypes. Concerning the high number of omics data currently generated, gene ontology is being improved into a more consistent and effective method towards the characterization of functional relationships between existing gene products (Gan et al., 2013; Gan, 2014; Gkoutos et al., 2017).

\section{Acknowledgments}

We dedicate this work to the late Prof. Dr. Jorge Jim, a zoologist with whom we have the honor of sharing its authorship. He has devoted his life to scientific knowledge and as an educator at the Department of Zoology of the São Paulo State University (UNESP), in Botucatu, São Paulo, Brazil. We thank Prof. Dr. Paulo Cesar Naoum, from the Laboratory of Hemoglobins and Hemoglobinopathies of the Department of Biology, UNESP-São José do Rio Preto, SP, Brazil for granting us access to the laboratory facilities; Prof. Dr. Arif Cais, from the Department of Zoology, UNESP-São José do Rio Preto, SP, Brazil, for allowing us access to the institution's valuable archives; Prof. Dr. Carlos Jared from the Laboratory of Cell Biology, Butantan Institute, São Paulo, for his assistance with the O. americanus photographic registry, to Ms. Fernanda Marceli da Silva Rosa from the Laboratory of Genetics, Butantan Institute for her assistance in typing the text. This work received financial support from the National Council for Scientific and Technological Development (CNPq), the Oswaldo
Cruz Foundation (FIOCRUZ), the Butantan Institute, and the Butantan Foundation.

\section{Conflict of interests}

The authors declare that there is no conflict of interest that could be perceived as prejudicial to the impartiality of the reported research.

\section{Author contributions}

AMC conceived and designed the study, AMC and CRBD conducted the experiments, AMC, CRBD, LDV, LSK, MLB and WB analyzed the data, AMC wrote the manuscript, MLB and WB reviewed the manuscript, all authors read and approved final version.

\section{References}

Aguiar MAM, Baranger M, Baptestini EM, Kaufman L and BarYam Y (2009) Global patterns of speciation and diversity. Nature 460:384-387.

Barale GD, Maria GA, di Tada IE and Lisanti JA (1981) Presencia de Odontophrynus americanus (Anura, Leptodactylidae) tetraploid en la província de Cordoba. Rev Univ Nac Río Cuarto 1:121-125.

Barrio A (1964) Caracteres eto-ecológicos diferenciales entre Odontophrynus americanus (Duméril et Bibron) y $O$. occidentalis (Berg) (Anura, Leptodactylidae). Physis 24:385-390.

Barrio A and Pistol de Rubel D (1972) Encuesta cariotipica de poblaciones argentino-uruguayas de Odontophrynus americanus (Anura, Leptodactylidae) relacionada com otros rasgos taxonômicos. Physis 31:281-291.

Batistic RF, Beçak W and Beçak ML (1973) DNA autoradiographic patterns in diploid, triploid and tetraploid amphibians (Ceratophrydidae). Cytologia 38:687-697.

Batistic RF, Soma M, Beçak ML and Beçak W (1975) Further studies on polyploid amphibians; a diploid population of Phyllomedusa burmeisteri. J Hered 66:160-162.

Beçak ML (2014) Polyploidy and epigenetic events in the evolution of Anura. Genet Mol Res 13:5995-6014.

Beçak ML and Beçak W (1970) Further studies on polyploid amphibians (Ceratophrydidae). III. Meiotic aspects of the interspecific triploid hybrid: Odontophrynus cultripes $(2 \mathrm{n}=22)$ O. americanus $(4 \mathrm{n}=44)$. Chromosoma 31:377-385.

Beçak ML and Beçak W (1974a) Diploidization in Eleutherodactylus(Leptodactylidae-Amphibia). Experientia 30:624-625.

Beçak ML and Beçak W (1974b) Studies on polyploidy amphibians - Karyotype evolution and phylogeny of the Genus Odontophrynus. J Herpetol 8:337-341.

Beçak ML and Beçak W (1998) Evolution by polyploidy in Amphibian: new insights. Cytogenet Cell Genet 80:28-33.

Beçak ML and Kobashi LS (2004) Evolution by polyploidy and gene regulation in Anura. Genet Mol Res 3:195-212.

Beçak ML, Beçak W and Rabello MN (1966) Cytological evidence of constant tetraploidy in the bisexual South American frog Odontophrynus americanus. Chromosoma 19:188-193. 
Beçak ML, Beçak W and Rabello MN (1967a) Further studies on polyploidy amphibians (Ceratophrydidae). I. Mitotic and meiotic aspects. Chromosoma 22:192-201.

Beçak W, Beçak ML, Lavalle D and Schreiber G (1967b) Further studies on polyploidy amphibians (Ceratophrydidae). II. DNA content and nuclear volume. Chromosoma 23:14-23.

Beçak ML, Beçak W and Vizotto LD (1970) A diploid population of the polyploid amphibian Odontophrynus americanus and an artificial intraspecific triploid hybrid. Experientia 26:545-546.

Bogart JP (1980) Evolutionary implications of polyploidy in amphibians and reptiles. In: Lewis WH (ed) Polyploidy: biological relevance. Plenum Press, New York, pp 341-378.

Bogart JP and Tandy M (1976) Polyploid amphibians: three more diploid-tetraploid cryptic species of frogs. Science 193:334-335.

Bogart JP and Wasserman AO (1972) Diploid-tetraploid crypt species pairs: a possible clue to evolution by polyploidization in Anura amphibians. Cytogenetics 11:7-24.

Butlin RK, Galindo J and Grahame JW (2008) Review. Sympatric, parapatric or allopatric: the most important way to classify speciation? Phil Trans R Soc Lond B Biol Sci 363:2997-3007.

Cei JM (1985) Un nuevo y peculiar Odontophrynus de la Sierra de Guasayan, Santiago del Estero, Argentina (Anura; Leptodactylidae). Cuad Herpetol 1:1-13.

Cianciarullo AM, Soares MJ and Beçak W (2000a) Erythropoiesis in the diploid and tetraploid Odontophrynus americanus: an evolutionary approach in these cryptic species (Amphibia, Anura, Leptodactylidae). Comp Haematol Int 10:19-29.

Cianciarullo AM, Naoum PC, Bertho AL, Kobashi LS, Beçak W and Soares MJ (2000b) Aspects of gene regulation in the diploid and tetraploid Odontophrynus americanus (Amphibia, Anura, Leptodactylidae). Genet Mol Biol 23:357-364.

Cristescu ME (2014) From barcoding single individuals to metabarcoding biological communities: towards an integrative approach to the study of global biodiversity. Trends Ecol Evol 29:566-571.

Deans AR, Lewis SE, Huala E, Anzaldo SS, Ashburner M, Balhoff JP, Blackburn DC, Blake JA, Burleigh JG, Chanet B et al. (2015) Finding our way through phenotypes. PLoS Biol 13:e1002033.

Ezaz T and Deakin JE (2014) Repetitive sequence and sex chromosome evolution in vertebrates. Adv Evol Biol 2014:104683.

Gan M (2014) Correlating information contents of gene ontology terms to infer semantic similarity of gene products. Comput Math Methods Med 2014:891842.

Gan M, Dou X and Jiang R (2013) From ontology to semantic similarity: calculation of ontology-based semantic similarity. Sci World J 2013:793091.

Gkoutos GV, Schofield PN and Hoehndorf R (2017) The anatomy of phenotype ontologies: principles, properties and applications. Brief Bioinform 2017:1-14.

Grenat PR, Salas NE and Martino AL (2012) Intra- and interspecific morphometric variation between Odontophrynus populations (Anura: Cycloramphidae) of central Argentina. Rev Biol Trop 60:1589-1601.

Huminiecki L and Conant GC (2012) Polyploidy and the evolution of complex traits. Int J Evol Biol 2012:292068.
Kobel HR and Pasquier LD (1986) Genetics of polyploid Xenopus. Trends Genet 2:310-315.

Leipoldt M and Schmidtke J (1982) Gene expression in phylogenetically polyploid organisms. In: Dover GA and Flavell RB (eds) Genome evolution. Academic Press, London, pp 219-236.

Lemos-Costa P, Martins AB, Thompson JN and de Aguiar MAM (2017) Gene flow and metacommunity arrangement affects coevolutionary dynamics at the mutualism-antagonism interface. J R Soc Interface 14:20160989.

Lewin HA, Robinson GE, Kress WJ, Baker WJ, Coddington J, Crandall KA, Durbin R, Edwards SV, Forest F, Gilbert MTP et al. (2018) Earth BioGenome Project: Sequencing life for the future of life. Proc Natl Acad Sci USA 115:4325-4333.

Mable BK and Bogart JP (1995) Hybridization between tetraploid and diploid species of tree frogs (Genus Hyla). J Heredity 86:432-440.

Mahoney M and Robinson ES (1980) Polyploidy in the Australian leptodactylid frog genus Neobatrachus. Chromosoma 81:199-212.

Marie Curie SPECIATION Network, Butlin R, Debelle A, Kerth C, Snook RR, Beukeboom LW, Castillo Cajas RF, Diao W, Maan ME, Paolucci S et al. (2012) What do we need to know about speciation? Trends Ecol Evol 27:27-39.

Martino AL and Sinsch U (2002) Speciation by polyploidy in Odontophrynus americanus. J Zool 257:67-81.

Martins AB, Aguiar MAM and Bar-Yam Y (2013) Evolution and stability of ring species. Proc Natl Acad Sci USA 110:5080-5084.

Miranda-Ribeiro A (1920) Algumas considerações sobre o gênero Ceratophrys e suas espécies. Rev Mus Paul 12:289-304.

Naoum PC (1990) Eletroforese: técnicas e diagnósticos. Livraria Santos, São Paulo, 174 p.

Ohno S (1970) Evolution by gene duplication. Springer-Verlag, New York, $160 \mathrm{p}$.

Pereyra MO, Marti DA, Lescano JN, Rosset SD and Baldo D (2009) Amphibia-Reptilia 30:571-575

Pyron RA and Wiens JJ (2011) A large-scale phylogeny of Amphibia including over 2800 species, and a revised classification of advanced frogs, salamanders, and caecilians. Mol Phylogenet Evol 61:543-583.

Rocha PC, Sena LMF, Pezzuti TL, Leite FSF, Svartman M, Rosset SD, Baldo D and Garcia PCA (2017) A new diploid species belonging to the Odontophrynus americanus species group (Anura: Odontophrynidae) from the Espinhaço range, Brazil. Zootaxa 4329:327-350.

Rosset SD (2008) New species of Odontophrynus Reinhardt and Lütken 1862 (Anura: Neobatrachia) from Brazil and Uruguay. J Herpetology 42:134-144.

Rosset SD, Baldo D and Haddad CFB (2009) Amphibia, Anura, Cycloramphidae, Odontophrynus lavillai: First record for Brazil and geographic distribution map. Check List 5:32-34.

Rosset SD, Baldo D, Lanzone C and Basso NG (2006) Review of the geographic distribution of diploid and tetraploid populations of the Odontophrynus americanus species complex (Anura: Leptodactylidae). J Herpetol 40:465-477.

Ruiz IRG, Bonaldo MF and Beçak W (1980) In situ localization of ribosomal genes in a natural triploid of Odontophrynus. J. Hered. 71:55-57.

Ruiz IRG, Soma M and Beçak W (1981) Nucleolar organizer regions and constitutive heterochromatin in polyploid species 
of the genus Odontophrynus (Amphibia, Anura). Cytogenet Cell Genet 29:84-98.

Ruiz IR, Almeida TMB and Beçak W (1984) Active nucleolar-organizer regions in polyploid populations of Odontophrynus americanus (Amphibia, Anura) from South Brazil. Genetica 63:31-37.

Sáez FA and Brum-Zorilla N (1966) Karyotype variation in some species of the genus Odontophrynus (Amphibia-Anura). Caryologia 19:55-63.

Savage JM (1973) The geographic distribution of frogs: patterns and predictions. In: Vial CJL (ed) Evolutionary biology of the anurans/Contemporary research on major problems. University of Missouri Press, Columbia, pp 352-445.

Savage JM and Cei JM (1965) A review of the Leptodactylid frog genus, Odontophrynus. Herpetologica 21:178-195.

Schwantes AR, Schwantes ML and Beçak W (1969) Electrophoretic patterns of G-6-PD, 6-PGD and LDH in polyploidy amphibians (Ceratophrydidae). Rev Bras Pesq Med Biol 2:14-44.

Schwantes ML, Schwantes AR and Beçak W (1977) Electrophoretic studies on polyploidy amphibians - I. 6-phosphogluconate dehydrogenase (6-PGD). Comp Biochem Physiol 56B:393-396.
Sparrow AH and Nauman AF (1976) Evolution of genome by DNA doublings. Science 192:524-529.

Tymowska J (1991) Polyploidy and cytogenetic variation in frogs of the genus Xenopus. In: Green DM and Sessions LK (eds) Amphibian cytogenetics and evolution. Academic Press, San Diego, pp 259-297.

Tymowska J and Fischberg M (1980) The karyotype of Xenopus wittei Tinsley, Kobel, and Fischberg, another tetraploid anuran species (Pipidae). Cytogenet Cell Genet 28:208-212.

Vogt L, Nickel M, Jenner RA and Deans AR (2013) The need for data standards in zoomorphology. J Morphol 274:793-808.

\section{Internet Resources Section}

Aquino L, Kwet A, Reichle S, Silvano D, Scott N, Lavilla E and di Tada I (2010) Odontophrynus americanus, The IUCN Red List of Threatened Species: e.T57186A86441009. http://dx.doi.org/10.2305/IUCN.UK.2010-2.RLTS.T57186 A11583471.en (accessed 05 August 2017)

Associate Editor: Fausto Foresti

License information: This is an open-access article distributed under the terms of the Creative Commons Attribution License (type CC-BY), which permits unrestricted use, distribution and reproduction in any medium, provided the original article is properly cited. 